\title{
Propafenone Poisoning-A Case Report with Plasma Propafenone Concentrations
}

\author{
Hanna Ovaska • Andrew Ludman • Edgar P. Spencer • \\ David M. Wood • Alison L. Jones • Paul I. Dargan
}

Published online: 7 April 2010

(C) American College of Medical Toxicology 2010

\begin{abstract}
Propafenone is an anti-arrhythmic drug used in the management of supraventricular and ventricular arrhythmias. It is metabolised through cytochrome P450 2D6 pathways; the major metabolites possess antiarrhythmic activity. The cytochrome P450 CYP2D6 is coded by more than 70 alleles resulting in great genetic polymorphism of CYP2D6 isoenzymes, and up to 7\% of Caucasian population are poor metabolisers. This case report describes a patient with severe overdose of propafenone who presented with coma, seizures and cardiotoxicity. The patient was managed with intravenous glucagon, hypertonic sodium bicarbonate, hypertonic saline and inotropic support. The propafenone and its 5-hydroxypropafenone (5-OHP) metabolite were measured by high-performance liquid chroma-
\end{abstract}

\section{H. Ovaska}

Clinical Toxicology Service, Guy's and St Thomas'

NHS Foundation Trust, London, UK

e-mail: Hanna.Ovaska@gstt.nhs.uk

A. Ludman

Queen Elizabeth Hospital, Woolwich, London, UK

E. P. Spencer

Medical Toxicology Laboratory, Guy's and St Thomas'

NHS Foundation Trust, London, UK

D. M. Wood • P. I. Dargan

Clinical Toxicology Service, Guy's and St Thomas'

NHS Foundation Trust and King's Health Partners,

London, UK

\section{M. Wood $(\bowtie)$}

Medical Toxicology Office, 2nd Floor,

Bermondsey Wing, Guy's Hospital, Great Maze Pond, London, SE1 9RT, UK

e-mail: David.Wood@gstt.nhs.uk

A. L. Jones

University of Newcastle, Newcastle, Australia tography with ultraviolet detection (no assay was available at the time to measure $N$-despropyl propafenone concentrations). Toxicological screen showed propafenone concentrations at a maximum of $1.26 \mathrm{mg} / \mathrm{L}$ at $9-10 \mathrm{~h}$ post-presentation, falling to $0.25 \mathrm{mg} / \mathrm{L}$ at $27-28 \mathrm{~h}$ postpresentation. No propafenone metabolite 5-OHP was detected in any sample analysed. No antidepressant or analgesic drugs were detected in toxicological screen. Propafenone overdose has been reported to be associated with features of severe cardiovascular and CNS toxicity. Aggressive treatment, meticulous monitoring and supportive care was associated with a good outcome in this case.

Keywords Propafenone $\cdot$ Poisoning $\cdot$ Cardiogenic shock · Convulsions

\section{Introduction}

Propafenone is a second-line agent in the treatment of resistant ventricular and supraventricular arrhythmias [1]. It is a class IC anti-arrhythmic under the Vaughan Williams classification, although it has additional beta receptor and calcium channel antagonist actions [2].

The principal metabolites of propafenone are 5hydroxypropafenone (5-OHP) and $N$-despropyl propafenone ( $N$-DPP). $18 \%$ of the parent compound is metabolised to 5 OHP, which is produced by the cytochrome P450-2D6 (CYP2D6) pathway; 23\% of the parent compound is metabolised to $N$-DPP, which is produced by $N$-dealkylation by both by CYP2D6 and non CYP2D6 P450 pathways $[3,4]$. Both 5-OHP and $N$-DPP have anti-arrhythmic activity; 5-OHP is almost equipotent to propafenone; however, the relative potency of $N$-DPP is poorly described $[3,5,6]$. 
The CYP2D6 is coded by gene M33388; more than 70 alleles have been described at the CYP2D6 locus resulting in the potential for numerous genetic polymorphisms of the CYP2D6 isoenzymes responsible for propafenone metabolism [7, 8]. As a result, up to 7\% of the Caucasian population are poor metabolisers (PM) of propafenone [9, 10]. Additionally, substantial dose-dependent metabolism of propafenone occurs in overdose; with higher concentrations of $N$-DPP than 5-OHP in the early stages of overdose, indicating a possible saturation of CYP2D6 metabolism to 5-OHP [11].

We describe here a patient who survived an episode of significant propafenone toxicity, together with data on plasma propafenone and 5-OHP concentrations.

\section{Case Report}

A 47-year-old male with a previous medical history of paroxysmal atrial fibrillation and absence seizures treated with propafenone and oxcarbamazepine, respectively, was brought to the Emergency Department (ED) having been found collapsed, vomiting and unresponsive at home. A note was found at the patient's home stating he had ingested propafenone and oxcarbamazepine, although the amount of each drug and the time of ingestion were unknown.

On arrival in the ED, he had a Glasgow Coma Scale of $9 / 15$ and was cardiovascularly compromised with a heart rate of $50 \mathrm{bpm}$ and blood pressure of $88 / 60 \mathrm{mmHg}$. His initial electrocardiogram (ECG) on arrival showed QRS prolongation to $160 \mathrm{~ms}$ and a corrected QT interval (QTc) of $487 \mathrm{~ms}$. Initial laboratory analyses revealed a normal full blood count, urea, creatinine, electrolytes, magnesium, glucose, creatine kinase, troponin $\mathrm{T}$, liver function and coagulation profile.

Within $30 \mathrm{~min}$ of arrival, he had a generalised tonicclonic seizure, which terminated following the administration of $2 \mathrm{mg}$ lorazepam intravenously. The patient was then intubated to protect his airway and mechanically ventilated without the need for sedation. He deteriorated rapidly with worsening of bradycardia and hypotension lasting for 15 min. A repeat ECG at this time showed further QRS and QTc prolongation to 240 and $560 \mathrm{~ms}$, respectively (Fig. 1). He then suffered a pulseless electrical activity (PEA) cardiac arrest. Cardiopulmonary resuscitation (CPR) was commenced according to current European Adult Cardiac Life Support guidelines. Following 5 cycles of CPR with a total of $4 \mathrm{mg}$ epinephrine, $100 \mathrm{ml} \mathrm{8.4 \%} \mathrm{Sodium}$ bicarbonate, $5 \mathrm{mg}$ glucagon and $4 \mathrm{~g}$ magnesium sulphate, return of spontaneous circulation (ROSC) was achieved with a blood pressure of $124 / 64 \mathrm{mmHg}$ and heart rate of $90 \mathrm{bpm}$. An arterial blood gas taken $35 \mathrm{~min}$ after the ROSC showed a metabolic acidosis $\left(\mathrm{pH} 7.21, \mathrm{pCO}_{2} 6.46, \mathrm{BE}-8.7\right.$ and bicarbonate $18.5 \mathrm{mmol} / \mathrm{L}$ ). A repeat 12 lead ECG taken 25 min post arrest showed further QRS and QTc prolongation to $240 \mathrm{~ms}$ and QTc $650 \mathrm{~ms}$, respectively.

The patient remained unstable over the next $120 \mathrm{~min}$ and further had five episodes of PEA cardiac arrest and an episode of asystolic cardiac arrest. During the resuscitation attempts, he received a total of $3 \mathrm{mg}$ of atropine, $9 \mathrm{mg}$ boluses of epinephrine, 2 boluses of $10 \mathrm{ml}$ of $30 \%$ (hyperosmolar) saline solution and an intravenous infusion of sodium bicarbonate $8.4 \%$ at $50 \mathrm{ml} / \mathrm{h}$ following initial boluses aiming to maintain $\mathrm{pH}$ greater than 7.5. Use of hypertonic sodium bicarbonate in the management of
Fig. 1 Peri-arrest ECG demonstrating QRS and QT prolongation

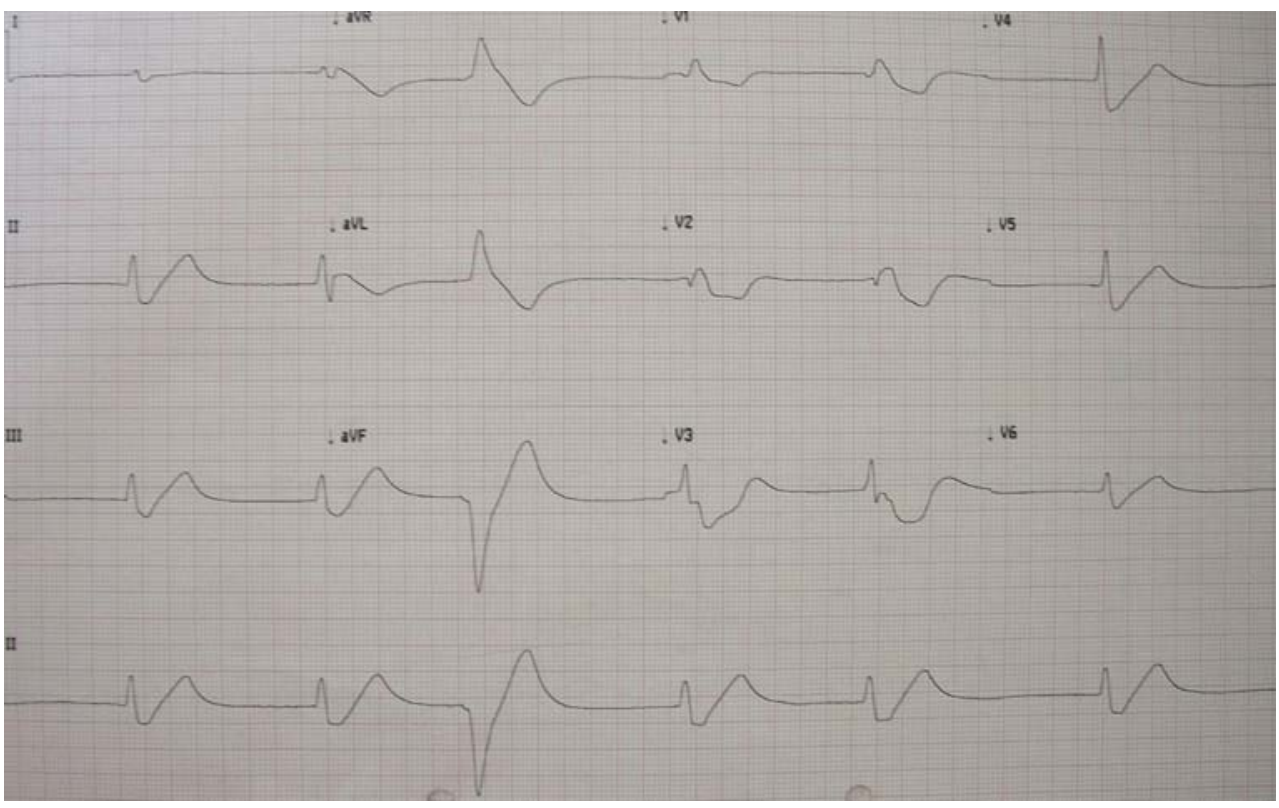


propafenone toxicity is extrapolated from its use in other Class IC anti-arrhythmic toxicity [12]. The total time of primary resuscitation was approximately $150 \mathrm{~min}$.

After initial stabilisation in the ED, the patient was transferred to the Intensive Care Unit for ongoing care. In view of the stated co-ingestion of oxcarbamazepine, the patient received multiple-dose activated charcoal via nasogastric tube, with the aim to enhance the oxcarbamazepine and its metabolite elimination and hence decrease the potential toxicity; $50 \mathrm{~g}$ of activated charcoal was given every $4 \mathrm{~h}$.

There was an initial good response to the above treatment with a heart rate of $90 \mathrm{bpm}$, and mean arterial pressure of $70 \mathrm{mmHg}$ was achieved. However, he remained cardiovascularly labile with fluctuating bradycardia and hypotension requiring epinephrine infusion (maximum infusion rate $0.45 \mu \mathrm{g} / \mathrm{kg} / \mathrm{min}$ ).

In view of the sodium channel effects of the propafenone ingested, he received an infusion of $60-100 \mathrm{ml} / \mathrm{h}$ of $8.4 \%$ sodium bicarbonate titrated to an arterial $\mathrm{pH}$ of greater than 7.5 (ventilation was adjusted to ensure a respiratory alkalosis occurred), with additional $1.8 \%$ sodium chloride titrated to a target serum sodium concentration of $150 \mathrm{mmol} / \mathrm{L}$. Over the first $24 \mathrm{~h}$, he had $1.2 \mathrm{~L}$ of $8.4 \%$ sodium bicarbonate solution and $1.8 \%$ sodium chloride, together with $240 \mathrm{mmol}$ of potassium and $40 \mathrm{mmol}$ of magnesium to maintain normal serum concentrations.

On the second day of admission, the patient began to improve and required sedation with intravenous propofol at $20-80 \mathrm{~mL} / \mathrm{h}$. He remained inotrope dependent with a maximum epinephrine infusion rate of $0.45 \mu \mathrm{g} / \mathrm{kg} / \mathrm{min}$. Despite his adequate haemodynamic status, he developed multi-organ dysfunction with acute renal (urea $11.2 \mathrm{mmol} / \mathrm{L}$, creatinine $231 \mu \mathrm{mol} / \mathrm{L}$ ) and liver (alanine transaminase $3,074 \mathrm{IU} / \mathrm{L}$ ) and an elevated serum lactate of $7 \mathrm{mmol} / \mathrm{L}$; all of these were presumed secondary to his prolonged resuscitation attempt, hypotension and poor tissue perfusion. $\mathrm{He}$ was changed from epinephrine to norepinephrine at a maximum rate of $0.5 \mu \mathrm{g} / \mathrm{kg} / \mathrm{min}$. A repeat 12 lead ECG $30 \mathrm{~h}$ post-presentation showed a normal QRS complex duration of $110 \mathrm{~ms}$ but a prolonged QTc interval at $489 \mathrm{~ms}$. As there was no further evidence of ongoing cardiovascular toxicity, the sodium bicarbonate and hypertonic saline infusions were discontinued at this stage.

Thirty-six hours after presentation, the patient had two short episodes of ventricular tachycardia (VT) and one episode of pulseless VT, which was successfully treated with $1 \mathrm{~min}$ of CPR and synchronised DC cardioversion $(200 \mathrm{~J})$ to sinus rhythm.

Over the next $48 \mathrm{~h}$, the inotropic support and sedation were gradually weaned, and he was extubated on day 3 . He developed atrial fibrillation on day 3 of his admission, which spontaneously reverted to sinus rhythm on day 5 . On day 4 , he had a normal transthoracic echocardiogram (off inotropic agents).

He was discharged from the intensive care unit on day 6 , with return to normal renal and liver function test and full neurological recovery, and transferred for inpatient psychiatry care on day 8.

Plasma Propafenone Concentrations and Toxicological Screening

Serial plasma samples for measurement of propafenone concentrations were taken during the admission. The samples were stored refrigerated at $+4^{\circ} \mathrm{C}$ until assayed within 5 working days. Both propafenone and 5-OHP are stable at room temperature under the chromatographic conditions used. Propafenone and 5-OHP were measured by highperformance liquid chromatography with ultraviolet (UV) detection (limit of detection 5-OHP $0.05 \mathrm{mg} / \mathrm{L}$ ). An internal standard solution and Tris buffer $(\mathrm{pH}$ 9.2) were added to plasma $(200 \mu \mathrm{L})$. Propafenone, 5-hydroxypropafenone and the internal standard were extracted into methyl-tert-butyl ether by vortex mixing and centrifugation. An aliquot of the extract was analysed by high-performance liquid chromatography using a Spherisorb S5SCX analytical column. Detection was by UV monitoring at $254 \mathrm{~nm}$. The concentration of the analytes in each sample was calculated from the calibration graph (peak height ratio of analyte to that of the internal standard against analyte concentration) obtained after analysis of plasma samples containing known amounts of propafenone and 5-hydroxypropafenone. The limit of accurate measurement of the assay or the lower limit of quantitation was $0.05 \mathrm{mg} / \mathrm{L}$ of either compound. Therapeutic plasma concentrations of propafenone and 5-OHP are in the range of $0.1-1.0 \mathrm{mg} / \mathrm{L}$; the patient's propafenone concentrations are shown in Table 1.

No carbamazepine or its metabolites were detected in any of the blood samples. A broad-based standard toxicology screen which covered, in particular, drugs known to cause QTc and QRS prolongation (e.g. tricyclic antidepressants, antihistamines, cocaine) did not detect any other compounds. A paracetamol (acetaminophen) concentration was negative.

Table 1 Propafenone and 5-hydroxypropafenone (5-OHP) concentrations (n/d-not detected (limit of detection $0.05 \mathrm{mg} / \mathrm{L})$ )

\begin{tabular}{lcl}
\hline Time & Propafenone $(\mathrm{mg} / \mathrm{L})$ & 5-OHP $(\mathrm{mg} / \mathrm{L})$ \\
\hline $9-10$ h post-presentation & 1.26 & $\mathrm{n} / \mathrm{d}$ \\
$19-20$ h post-presentation & 0.33 & $\mathrm{n} / \mathrm{d}$ \\
$27-28$ h post-presentation & 0.25 & $\mathrm{n} / \mathrm{d}$ \\
\hline
\end{tabular}




\section{Discussion}

We describe here a patient who developed significant cardiac toxicity with multiple cardiac arrests in the ED, likely to be due to significant propafenone toxicity. He was managed with respiratory support, administration of hypertonic $(8.4 \%)$ sodium bicarbonate, hypertonic (1.8\%) sodium, glucagon, magnesium, epinephrine/norepinephrine and DC cardioversion. There are a number of previous reports of propafenone poisoning, with similar life-threatening symptoms in which cardiac features predominate with QRS/QTc prolongation and ventricular arrhythmias [11, 13-17]. However, seizures have been reported in one case of severe propafenone poisoning [16].

Propafenone is metabolised in the liver via the cytochrome P450 2D6 (CYP2D6) pathway to two major metabolites: 5hydroxypropafenone (5-OHP) and $N$-despropyl propafenone ( $N$-DPP). $N$-DPP is also formed by CYP3A4-, CYP1A2- and CYP1A1-mediated $N$-dealkylation [4]. Genetic polymorphisms in CYP2D6 activity result in variable propafenone metabolism [18]. Patients can be categorised as either extensive metabolisers (EM) or PM of propafenone [18]. EM are characterised by a short propafenone half-life $\left(\mathrm{T}_{1 / 2}\right)$ $5.5 \pm 2.1 \mathrm{~h}$ and lower plasma propafenone concentrations with detectable concentrations of the major metabolite 5-OHP [18]. PM, whose functional activity of CYP2D6 is reduced, have prolonged propafenone $T_{1 / 2}(17.2 \pm 8.0 \mathrm{~h})$, and typically, they have undetectable plasma concentrations of the 5-OHP metabolite [18]. PM are more likely to have cardiovascular and neurological adverse effects than EM [18, 19].

The initial plasma propafenone concentration in our patient approximately $10 \mathrm{~h}$ post-presentation was $1.26 \mathrm{mg} / \mathrm{L}$ (therapeutic range $0.1-1.0 \mathrm{mg} / \mathrm{L})$. Although the plasma concentration of propafenone was slightly elevated compared to therapeutic range, there were no other drugs detected that could explain the severe cardiotoxicity. 5-OHP was not detected in any of the samples taken post-presentation, and we were unable to measure $N$-DPP. There is the possibility that our patient had a CYP2D6 polymorphism resulting in a PM phenotype as an explanation for the undetectable 5-OHP. We postulate that this may have resulted in greater metabolism to the $N$-DPP metabolite; this is an active metabolite, but its relative potency and toxicity are poorly understood [7-11]. However, there are a number of limitations not least that this is a single case report, and we have been unable to measure the $N$-DPP metabolite.

This case highlights the potential for severe cardiotoxicity associated with propafenone poisoning. More information is required on the relative potencies of the metabolites, particularly $N$-DPP. Data on the relative toxicity of propafenone and its metabolites in extensive and poor metabolisers may be useful in allowing more appropriate and targeted use of propafenone in the future.
Conflict of interest The authors declare that they have no competing interests.

Funding There were no sources of funding for this study.

\section{References}

1. National Institute for Health and Clinical Excellence (2006) NICE clinical guideline 36-atrial fibrillation: the management of atrial fibrillation. http://www.nice.org.uk/nicemedia/pdf/CG036nice guideline.pdf. Accessed 30 Jan 2009

2. Anon (1999) Propafenone (hydrochloride). In: Dollery C, Boobis A (eds) Therapeutics and drugs, 2nd edn. Churchill Livingstone Inc, London, pp 243-248

3. Afshar M, Thormann W (2006) Capillary electrophoretic investigation of the enantioselective metabolism of propafenone by human cytochrome P-450 SUPERSOMES: evidence for atypical kinetics by CYP2D6 and CYP3A4. Electrophoresis 27:1526-1536

4. Cahill SA, Gross GJ (2004) Propafenone and its metabolites preferentially inhibit $\mathrm{IKr}$ in rabbit ventricular myocytes. J Pharmacol Exp Ther 308:59-65

5. Siddoway LA, Roden DM, Woosley RL (1984) Clinical pharmacology of propafenone: pharmacokinetics, metabolism and concentration-response. Am J Cardiol 54:9D-12D

6. Connolly SJ, Kates RE, Lebsack CS, Harrison DC, Winkle RA (1983) Clinical pharmacology of propafenone. Circulation 68:589-596

7. CYP2D6 Allele Nomenclature (2008) http://www.cypalleles.ki.se/ cyp2d6.htm. Accessed 30 Jan 2009

8. Pirmohamed M, Park BK (2003) Cytochrome P450 enzyme polymorphism and adverse drug reactions. Toxicology 192:23-32

9. Evans DA, Mahgoub A, Sloan TP, Idle JR, Smith RL (1980) A family and population study of the genetic polymorphism of debrisoquine oxidation in a white British population. J Med Genet 17:102-105

10. Steiner E, Iselius L, Alván G, Lindsten J, Sjöqvist F (1985) A family study of genetic and environmental factors determining polymorphic hydroxylation of debrisoquine. Clin Pharm Ther 38:394-401

11. Fonck K, Haenebalcke C, Hemeryck A, Belpaire F, Jordaens L, Calle P, Buylaert W (1998) ECG changes and plasma concentrations of propafenone and its metabolites in a case of severe poisoning. J Toxicol Clin Toxicol 36:247-251

12. Keyler DE, Pentel PR (1989) Hypertonic sodium bicarbonate partially reverses QRS prolongation due to flecainide in rats. Life Sci 45:1575-1580

13. Clarot F, Goullé JP, Horst M, Vaz E, Lacroix C, Proust B (2003) Fatal propafenone overdoses: case reports and a review of the literature. J Anal Toxicol 27:595-599

14. Eray O, Fowler J (2000) Severe propafenone poisoning responded to temporary internal pacemaker. Vet Hum Toxicol 42:289

15. Kerns W, English B, Ford M (1994) Propafenone overdose. Ann Emerg Med 24:98-103

16. Rambourg-Schepens MO, Grossenbacher F, Buffet M, Lamiable D (1999) Recurrent convulsions and cardiac conduction disturbances after propafenone overdose. Vet Hum Toxicol 41:153

17. Hasdemir C, Olukman M, Ulucan C, Roden DM (2006) Brugadatype ECG pattern and extreme QRS complex widening with propafenone overdose. J Cardiovasc Electrophysiol 17:565-566

18. Siddoway LA, Thompson KA, McAllister CB, Wang T, Wilkinson GR, Roden DM, Woosley RL (1987) Circulation polymorphism of propafenone metabolism and disposition in man: clinical and pharmacokinetic consequences. Circulation 75:785-791

19. Lee JT, Lineberry MD, Funck-Bretano C (1988) Propafenone induced beta-blockade in extensive and poor metaboliser subjects. Circulation 78:499 